\title{
População de plantas de milho consorciado com Urochloa ruziziensis ${ }^{1}$
}

\author{
Roberto José de Freitas², Adriano Stephan Nascente ${ }^{3}$, Fenelon Lourenço de Sousa Santos ${ }^{2}$
}

\begin{abstract}
Population of maize plants

intercropped with Urochloa ruziziensis

The no-tillage system (NTS) is a sustainable technique that encourages the maintenance of crop residues on the soil surface. However, the straw produced by commercial crops is insufficient to keep the soil covered throughout the year. Thus, the intercropping of maize and Urochloa ruziziensis is a viable alternative that could increase the biomass production per area, and consequently the amount of straw, aiming the NTS. Identifying the correct density for intercropped maize plants is very important and can help to increase the accumulation of forage plants biomass, without negatively affecting maize grain yield. So, this study aimed at evaluating the effect of maize plants densities in the cropping performance, intercropped or not with U. ruziziensis. The experimental design was randomized complete blocks, in a $4 \times 2$ factorial scheme (maize plants populations $\mathrm{x}$ cropping systems - single and intercropped maize). Maize yield, yield components and forage biomass were evaluated. The maize grain yield was not affected by the intercropping with $U$. ruziziensis. Increasing maize plants densities (up to 80,000 plants ha $^{-1}$ ) provided a reduction in the number of ears plant ${ }^{-1}$ and grains per ear row ${ }^{-1}$, however, resulted in a higher grain yield. The forage biomass from $U$. ruziziensis intercropped off-season with maize decreased, while the maize plant density increased up to 80,000 plants ha ${ }^{-1}$. In the absence of hidric restriction, the density of 80,000 maize plants $\mathrm{ha}^{-1}$ is the recommended one.
\end{abstract}

KEY-WORDS: Zea mays L.; forage plants; crop-livestock integration.

\section{INTRODUÇÃO}

O sistema plantio direto (SPD) preconiza a conservação dos recursos naturais, baseando-se no não revolvimento do solo, na manutenção de palhada em sua superfície, no uso de semeadoras específicas, na rotação de culturas e, mais recentemente, na

\section{RESUMO}

O sistema plantio direto (SPD) é uma técnica sustentável que preconiza a manutenção da palhada na superfície do solo. Entretanto, os resíduos vegetais produzidos pelas culturas comerciais são insuficientes para manter o solo coberto, durante o ano. Assim, o consórcio de milho com Urochloa ruziziensis é uma alternativa viável, que pode aumentar a massa vegetal por área, com consequente aumento na palhada, visando ao SPD. De suma importância no consórcio, a identificação da correta densidade de plantas de cultivo de milho poderá proporcionar incremento no acúmulo da biomassa da planta forrageira, sem prejuízo à produtividade do cereal. Desta forma, objetivou-se avaliar o efeito da população de plantas de milho no desempenho da cultura, com ou sem consórcio com $U$. ruziziensis. $\mathrm{O}$ delineamento experimental foi o de blocos completos casualizados, em esquema fatorial $4 \times 2$ (populações de plantas de milho x métodos de cultivo - milho solteiro e consorciado). Avaliaram-se os componentes de produção, produtividade do milho e massa da forragem, sendo que a produtividade de grãos de milho não foi alterada pelo consórcio com U. ruziziensis. Maiores populações de milho (até 80.000 plantas ha ${ }^{-1}$ ) proporcionaram redução no número de espigas planta ${ }^{-1}$ e grãos fileira ${ }^{-1}$, na espiga, porém, possibilitaram maior produtividade de grãos, na área cultivada. A massa de forragem de U. ruziziensis, em cultivo consorciado com o milho, em safrinha, foi reduzida à medida em que aumentou-se a população até 80.000 plantas ha ${ }^{-1}$. Na ausência de restrição hídrica, recomenda-se a densidade de 80.000 plantas de milho ha ${ }^{-1}$.

PALAVRAS-CHAVE: Zea mays L.; plantas forrageiras; integração lavoura-pecuária.

adoção da integração lavoura-pecuária (ILP) (Scaléa 2007, Barducci et al. 2009, Crusciol et al. 2010).

Atualmente, a ILP praticada em SPD constitui-se em uma das melhores alternativas para se conduzir os sistemas agrícolas tropicais rumo à sustentabilidade, podendo resultar em diversidade de produção, maiores retornos econômicos e melhoria

1. Trabalho recebido em set./2012 e aceito para publicação em mar./2013 ( $\mathrm{n}^{\circ}$ registro: PAT 20284).

2. Universidade Estadual de Goiás (UEG), Unidade Universitária de Ipameri, Ipameri, GO, Brasil. E-mails: rjf05@uol.com.br, fenelon@hotmail.com.

3. Empresa Brasileira de Pesquisa Agropecuária (Embrapa Arroz e Feijão), Santo Antônio de Goiás, GO, Brasil. 
das condições ambientais de cultivo, com ênfase na ciclagem de nutrientes (Castro Filho et al. 1991, Vilela et al. 2001, Kluthcouski et al. 2003, Garcia et al. 2008, Carvalho et al. 2010, Crusciol et al. 2010, Nascente et al. 2011, Nascente \& Crusciol 2012).

Os resíduos produzidos por culturas comerciais, geralmente, são insuficientes para uma boa cobertura do solo. Além disto, em regiões tropicais onde o inverno é seco e as temperaturas elevadas, ocorre rápida decomposição da palhada, o que se torna um fator limitante, que dificulta a manutenção da cobertura de palha sobre o solo por maiores períodos, comprometendo a sustentabilidade do SPD (Crusciol et al. 2010, Pacheco et al. 2011).

Dessa forma, faz-se necessário introduzir plantas capazes de produzir grande quantidade de massa seca, de modo que o solo permaneça coberto o maior tempo possível, para a implantação da próxima cultura de verão (Borghi \& Crusciol 2007, Pariz et al. 2009).

Como alternativa, tem-se o cultivo consorciado de culturas graníferas (como o milho, soja, arroz, feijão e sorgo) com forrageiras tropicais (Kluthcouski et al. 2003). Neste sistema, a forrageira produzida pode ser utilizada para a alimentação animal, no período de entressafra, ou como palhada, no SPD (Nascente \& Crusciol 2012).

Dentre esses consórcios, o mais comum é o realizado com milho e brachiaria (Cobucci 2001, Borghi \& Crusciol 2007, Freitas et al. 2008, Pariz et al. 2009). Isto ocorre devido à tradição no cultivo de milho, ao grande número de cultivares comerciais adaptadas às diferentes regiões ecológicas do Brasil, à excelente adaptação (quando utilizado em consórcio) e à facilidade de cultivo (Freitas et al. 2008).

O sucesso na utilização das brachiarias de origem africana decorre do seu sistema radicular profundo (aproximadamente 2,0 m), da considerável tolerância à deficiência hídrica, em comparação às espécies produtoras de grãos, e da grande produção de massa seca, podendo chegar a $20,0 \mathrm{t} \mathrm{ha}^{-1}$ (Kluthcouski et al. 2000, Cobucci 2001, Santos et al. 2007, Barducci et al. 2009, Valle \& Pagliarini 2009, Ferreira et al. 2010, Crusciol et al. 2012).

Como a brachiaria apresenta crescimento inicial lento (Freitas et al. 2008, Valle \& Pagliarini 2009), ela não afeta o crescimento inicial da cultura do milho e, na maioria dos casos, não interfere na produtividade de grãos (Cobucci 2001, Barducci et al. 2009). No entanto, a capacidade competitiva do milho depende da população utilizada e das características morfológicas da cultivar, como altura da planta e conformação das folhas, além do suprimento adequado de nutrientes (Lara-Cabezas \& Pádua 2007, Freitas et al. 2008).

A população de plantas de milho exerce reflexos diretos na produtividade da cultura e, também, na produção da forrageira (Crusciol et al. 2010). Sangoi (2001), Marchão et al. (2005) e Calonego et al. (2011) relataram incrementos na produtividade de grãos de milho com densidades superiores a 70.000 plantas ha $^{-1}$, entretanto, são trabalhos com milho solteiro.

Estudos relacionados à densidade de plantio de milho em consórcios são incipientes. Desconhecem-se os efeitos da densidade de plantio do milho no desempenho do consórcio, seja na produtividade do milho ou da forrageira. Segundo Ceccon (2008), o acúmulo de biomassa pela forrageira, quando consorciada com o milho, na safrinha (46.000 plantas ha-1, com média de $1.611 \mathrm{~kg} \mathrm{ha}^{-1}$ de MS), foi pequeno. Entretanto, no período chuvoso subsequente, a forrageira, por ter hábito perene, já está formada e, rapidamente, retoma o crescimento, acumulando matéria seca, para ser utilizada como palha no SPD.

Diante do exposto, objetivou-se avaliar o desempenho produtivo do consórcio de diferentes populações de milho com U. ruziziensis.

\section{MATERIAL E MÉTODOS}

O experimento foi desenvolvido na Fazenda Santa Brígida, em Ipameri, GO (17\%43'19'S, 48 09'36"W e altitude aproximada de $815 \mathrm{~m}$ ), em área anteriormente cultivada com soja, em SPD. O solo utilizado é classificado como Latossolo Vermelho distrófico típico, com textura argilosa (Embrapa 2006a), sendo as características químicas e granulométricas avaliadas antes da instalação do experimento (Tabela 1). O clima local é classificado como Cwa, tropical de altitude, segundo Köppen, e, adicionalmente, foi feito o monitoramento da precipitação pluvial ocorrida na área do experimento (Tabela 2), localizada na sede da propriedade, a 300,0 $\mathrm{m}$ do experimento.

O delineamento experimental utilizado foi o de blocos completos casualizados, em esquema fatorial 4x2, com três repetições. Os tratamentos constituíram-se de quatro populações de plantas de milho (20.000 plantas ha-1 40.000 plantas $\mathrm{ha}^{-1}$, 
Tabela 1. Características químicas e granulométricas da área experimental (0-0,20 m) (Ipameri, GO, 2012).

\begin{tabular}{|c|c|c|c|c|c|c|c|c|c|c|c|c|c|c|c|}
\hline \multirow{2}{*}{$\begin{array}{c}\mathrm{pH} \\
\mathrm{CaCl}_{2}\end{array}$} & \multirow{2}{*}{$\frac{\mathrm{P}(\text { Mehlich })}{\mathrm{mg} \mathrm{dm}^{-3}}$} & $\mathrm{Ca}$ & $\mathrm{Mg}$ & $\mathrm{K}$ & $\mathrm{H}+\mathrm{Al}$ & CTC & \multirow{2}{*}{$\frac{\mathrm{V}}{\%}$} & M.O. & $\mathrm{B}$ & $\mathrm{Cu}$ & $\mathrm{Mn}$ & $\mathrm{Zn}$ & \multirow{2}{*}{\multicolumn{3}{|c|}{$\begin{array}{ccc}\text { Argila } & \text { Silte } & \text { Areia } \\
& \mathrm{g} \mathrm{kg}^{-1} & \end{array}$}} \\
\hline & & \multicolumn{5}{|c|}{$\mathrm{cmol}_{\mathrm{c}} \mathrm{dm}^{-}$} & & \multicolumn{5}{|c|}{$\mathrm{mg} \mathrm{dm}^{-3}$} & & & \\
\hline 5,5 & 7,7 & 2,1 & 0,8 & 0,18 & 1,8 & 4,89 & 63,2 & 2,1 & 0,20 & 2,1 & 24,1 & 5,7 & 420,0 & 110,0 & 470,0 \\
\hline
\end{tabular}

Tabela 2. Precipitações pluviais da média histórica (24 anos) e do ano de 2012, no período de condução do experimento (Ipameri, GO, 2012).

\begin{tabular}{lrrrrr}
\hline \multirow{2}{*}{ Período } & Fevereiro & Março & Abril & Maio & Junho \\
\cline { 2 - 5 } & \multicolumn{5}{c}{ mm } \\
\hline 2012 & 198,0 & 106,5 & 115,5 & 68,0 & 54,0 \\
$1988 / 2011$ & 191,0 & 175,9 & 49,9 & 35,3 & 4,0 \\
\hline
\end{tabular}

Fonte: Inmet (2012).

60.000 plantas ha-1 e 80.000 plantas ha ${ }^{-1}$ ) e dois sistemas de cultivo (milho solteiro e consorciado com U. ruziziensis). Cada parcela foi constituída por seis linhas de 5,0 $\mathrm{m}$ de comprimento, espaçadas em $0,50 \mathrm{~m}$, perfazendo uma área total de $15,0 \mathrm{~m}^{2}$. Como área útil da parcela, foram consideradas as duas linhas centrais, sendo que $1,0 \mathrm{~m}$ da extremidade de cada linha de plantas e as duas linhas externas constituíram-se na bordadura.

O milho foi semeado em SPD, sobre a palhada de soja, sendo a área dessecada com a aplicação de glifosato (1.800 $\mathrm{g} \mathrm{ha}^{-1}$ do ingrediente ativo), com volume de calda de $120 \mathrm{~L} \mathrm{ha}^{-1}$, em pré-semeadura. A semeadura do híbrido de milho simples Syngenta Impacto $^{\circledR}$ (material recomendado para a região), nos dois sistemas de produção, foi realizada no dia 27 de fevereiro de 2012, por meio de semeadora-adubadora, para plantio direto com 10 linhas, visando a atingir a população de 80.000 plantas ha $^{-1}$, sendo que, 10 dias após a semeadura, foi feito o desbaste da cultura, deixando-se a população pré-estabelecida, para cada tratamento.

A adubação de semeadura foi constituída por $150,0 \mathrm{~kg} \mathrm{ha}^{-1}$ de fosfato monoamônio, não sendo utilizado $\mathrm{K}_{2} \mathrm{O}$ na semeadura, devido ao risco do investimento em condições de segunda safra. Por ocasião da adubação de cobertura, foram utilizados $150,0 \mathrm{~kg} \mathrm{ha}^{-1}$ da fórmula 36-00-12, no estádio fenológico $\mathrm{V}_{3}$ do milho. A adubação descrita anteriormente e o controle de pragas, doenças e plantas daninhas foram realizados de acordo com as necessidades da cultura (Embrapa 2006b).

Utilizou-se $3,2 \mathrm{~kg} \mathrm{ha}^{-1}$ de sementes puras viáveis ( 320 pontos de crescimento $\mathrm{m}^{-2}$ ) de $U$.ruziziensis.
A semeadura da brachiaria ocorreu simultaneamente à do milho, com utilização da terceira caixa da semeadora, específica para tal finalidade. Desta forma, as sementes foram aplicadas a lanço e incorporadas pelo revolvimento do solo, efetuado pela semeadora-adubadora. Aos 15 dias após a semeadura (DAS), efetuou-se a capina manual da brachiaria emergida nas parcelas sem o consórcio, sendo esta capina repetida aos 30 DAS do milho, em todas as parcelas, para eliminar plantas daninhas.

A colheita do milho foi realizada manualmente, aos 115 DAS, coletando-se todas as espigas na área útil de cada parcela. A seguir, realizou-se a trilha mecânica e determinação da umidade das amostras, com o auxílio de aparelho AgraTronix MT16, corrigida para $13 \%$. Nesta ocasião, determinou-se, também, a altura média das plantas, altura de inserção da primeira espiga, número de espigas $\mathrm{m}^{-2}$, número de espigas planta $^{-1}$, número de fileiras de grãos espiga ${ }^{-1}$, número de grãos fileira ${ }^{-1}$ e massa de 100 grãos.

A massa da forragem de $U$. ruziziensis foi determinada com o auxílio de quadro de amostragem de $1,0 \mathrm{~m}^{2}$, consistindo da média de quatro amostragens aleatórias por parcela, com todo o material coletado sendo pré-seco em estufa de circulação forçada de ar $\left(65^{\circ} \mathrm{C}\right)$. Em seguida, realizou-se a pesagem e o cálculo da massa da forragem $\left(\mathrm{kg} \mathrm{ha}^{-1}\right.$ de matéria seca).

Os cortes foram realizados com o uso da ceifa da forrageira, cortando-se a forragem à altura de $0,20 \mathrm{~m}$, em relação à superfície do solo. A primeira ceifa da forrageira foi efetuada logo após a colheita do milho (115 DAS do cereal - 25/06/2012, em sua maturação fisiológica) e a segunda após 60 dias (25/08/2012).

Os dados foram submetidos à análise de variância e análise de regressão, para o fator população de plantas. População de plantas de milho e sistema de cultivo (consorciado ou solteiro) foram considerados fatores fixos.

\section{RESULTADOS E DISCUSSÃO}

Durante a condução do experimento, ocorreu precipitação pluvial de 542,0 mm (Tabela 2). Assim, 
apesar de o objetivo inicial do trabalho ter sido avaliar o desempenho do consórcio testado, nas diversas populações do milho, em condições de restrição hídrica, na fase reprodutiva da cultura, como é típico das condições de $2^{\mathrm{a}}$ safra (outonal), no ano de 2012, ocorreram precipitações acima da média, na região, uma vez que a média histórica é de 456,0 mm. De acordo com Bergamaschi et al. (2004), este volume de precipitação pluvial, quando bem distribuído, não causando limitação em estádios críticos da cultura, proporciona o pleno desenvolvimento do milho sem déficit hídrico, como observado no presente experimento. Neste sentido, pode-se inferir que o milho teve crescimento e desenvolvimento similares aos das condições de safra das águas, ou seja, sem restrição hídrica.

Houve efeito da população de plantas sobre quase todas as características avaliadas, contudo, não houve efeito do sistema de cultivo e nem da interação dos fatores sobre as variáveis analisadas (Tabela 3 ). As únicas exceções foram o número de fileiras de grãos por espiga e massa de 100 grãos, que não foram afetados pelos fatores.

Ocorreu aumento linear na altura de plantas e altura de inserção da primeira espiga, com o aumento da população de plantas (Figuras 1a e 1b, respectivamente). Estas variáveis, normalmente, estão relacionadas às características morfológicas, fisiológicas e fenológicas inerentes a cada genótipo (Sangoi et al. 2001). Entretanto, a maior população de plantas pode aumentar a competição entre as plantas e proporcionar o seu estiolamento (Demétrio et al. 2008).

Penariol et al. (2003), Marchão et al. (2005), Alvarez et al. (2006) e Calonego et al. (2011) relataram incremento na altura de plantas e da primeira espiga, com as maiores populações de plantas de milho. Penariol et al. (2003) trabalhou com híbridos de milho, em espaçamento de 0,40-0,80 $\mathrm{m}$ e com
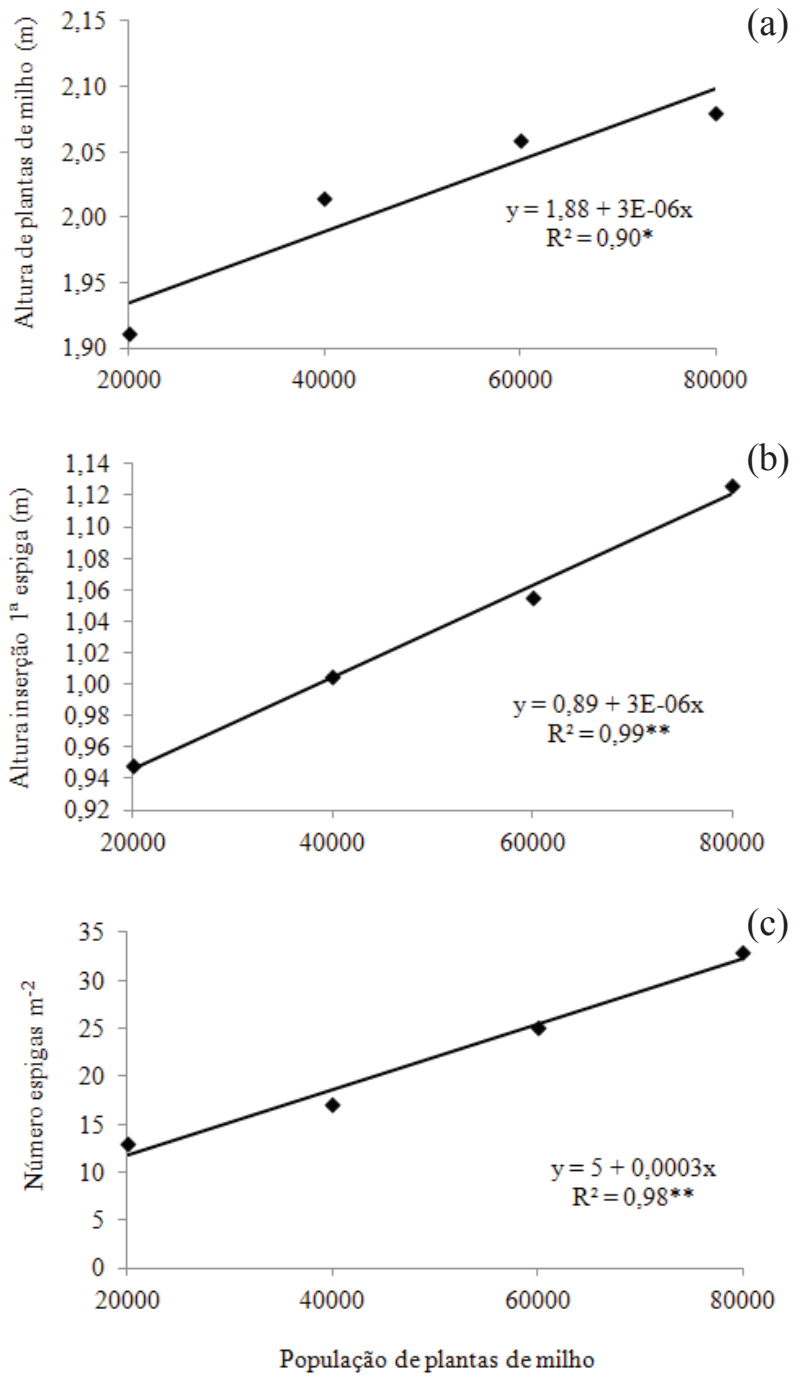

Figura 1. Altura de plantas (a) e de inserção da primeira espiga (b) e número de espigas $\mathrm{m}^{-2}$ (c) de plantas de milho, em função da densidade populacional (Ipameri, GO, 2012).

densidades de 40.000-80.000 plantas ha ${ }^{-1}$, na safrinha. Marchão et al. (2005) estudaram sete híbridos de milho, no espaçamento de $0,45 \mathrm{~m}$ e com densidades

Tabela 3. Valores de probabilidade do teste F, para altura de plantas (AP), altura de inserção da espiga (AIE), número de espigas m² (NEM) e de espigas planta ${ }^{-1}$ (NEP), número de fileiras de grãos espiga ${ }^{-1}$ (NFE) e de grãos fileira ${ }^{-1}$ (NGF), massa de 100 grãos (MG) e produtividade de grãos (PG) de milho e massa da forragem de Brachiaria ruziziensis (MSB), em função da população de plantas de milho (POP) e do sistema de cultivo (SC) (Ipameri, GO, 2012).

\begin{tabular}{lcccccccccc}
\hline $\begin{array}{c}\text { Fontes de } \\
\text { Variação }\end{array}$ & AP & AIE & NEM & NEP & NFE & NGF & MG & PG & MSB \\
\hline POP & $<0,01$ & $<0,01$ & $<0,01$ & $<0,01$ & 0,2213 & $<0,01$ & 0,2478 & $<0,01$ & $<0,01$ \\
SC & 0,2165 & 0,2435 & 0,2981 & 0,2664 & 0,2998 & 0,2731 & 0,3173 & 0,1174 & - \\
POP x SC & 0,3547 & 0,3102 & 0,4357 & 0,3276 & 0,4429 & 0,4007 & 0,5108 & 0,3211 & - \\
\hline C.V. $(\%)$ & 4,3 & 8,2 & 1,2 & 3,5 & 3,2 & 9,7 & 4,7 & 11,3 & 9,8 \\
\hline
\end{tabular}


de 40.000-100.000 plantas ha ${ }^{-1}$, na safra das águas. Alvarez et al. (2006) avaliaram três híbridos de milho, em dois espaçamentos $(0,70 \mathrm{~m}$ e $0,9 \mathrm{~m})$ e densidades de 55.000-75.000 plantas ha-1 ${ }^{-1}$ na safra das águas. Calonego et al. (2011) estudaram um híbrido de milho, nos espaçamentos de $0,45 \mathrm{~m}$ e $0,90 \mathrm{~m}$ e com

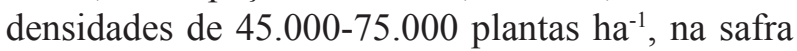
das águas. Com base nos resultados, pode-se inferir que o aumento da densidade de plantas de milho ha $^{-1}$ proporciona incrementos na altura de plantas e de inserção da primeira espiga, independentemente da época de implantação da cultura e do espaçamento utilizado.

Plantas com maior altura de inserção da espiga, desde que não proporcionem acamamento das plantas, favorecem a colheita mecanizada, reduzindo o percentual de espigas não colhidas pela plataforma da colhedora. Além disto, o aumento da inserção da espiga, no sistema consorciado, pode ser benéfico, desde que não proporcione redução na produtividade de grãos, pois acarreta em aumento na altura da plataforma de corte, com ceifa mais alta e, consequentemente, menor quantidade de forragem e, portanto, com menor tempo de vedação da área, para a introdução de animais ao primeiro pastejo (Crusciol et al. 2010).

Com relação ao número de espigas $\mathrm{m}^{-2}$, constatou-se, também, incrementos lineares, em função do aumento da população de plantas (Figura 1c). Assim, a maior densidade de plantas proporcionou maior produção de espigas por área. Por outro lado, para o número de espigas planta ${ }^{-1}$, verificou-se ajuste dos dados a uma equação polinomial de segundo grau, sendo os maiores valores obtidos na menor população de plantas (Figura 2a).

De acordo com Calonego et al. (2011) e Sangoi (2001), a utilização de menores populações de plantas acarreta na redução da eficiência de interceptação da radiação solar, em determinada área, proporcionando aumento na produção de grãos por indivíduo, havendo, entretanto, redução na produtividade por área. Por outro lado, a maior densidade de plantas proporciona maior produção por área e redução na produtividade por indivíduo.

$\mathrm{O}$ número de fileiras de grãos espiga-1 ${ }^{-1}$ a massa de 100 grãos não foram influenciados pelas densidades de cultivo (Figuras $2 \mathrm{~b}$ e $3 \mathrm{a}$, respectivamente). O número de fileiras de grãos espiga ${ }^{-1}$ tem grande controle genético e, por isto, normalmente, é pouco influenciado por fatores externos. Entretanto,

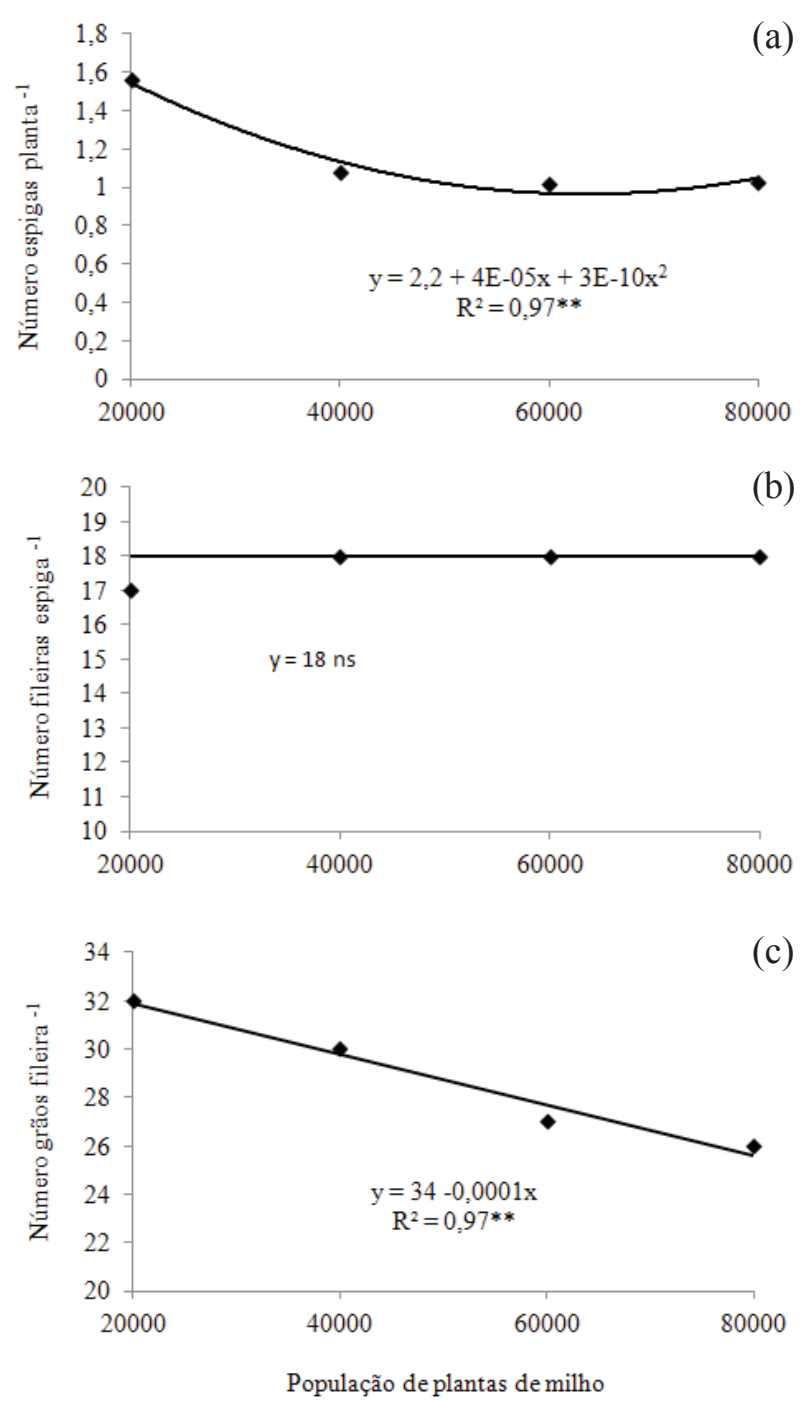

Figura 2. Número de espigas planta-1 (a), de fileiras de grãos espiga $^{-1}$ (b) e de grãos fileira-1 (c) de plantas de milho, em função da densidade populacional (Ipameri, GO, 2012).

a massa de 100 grãos é mais influenciada pelos fatores do meio (Embrapa 2006b), assim, seria de se esperar redução nesta característica, caso houvesse limitação hídrica ou intensa redução no crescimento das plantas, o que não ocorreu, no presente experimento.

Resultados semelhantes foram obtidos por Pereira et al. (2009), os quais cultivaram milho irrigado consorciado com $U$. decumbens, no espaçamento de

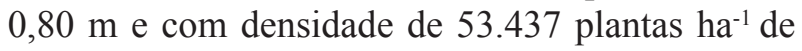
milho, e verificaram que o consórcio não afetou os componentes de produção do milho. Por outro lado, o número de grãos fileira ${ }^{-1}$ teve queda linear, com o aumento da população (Figura 2c). 

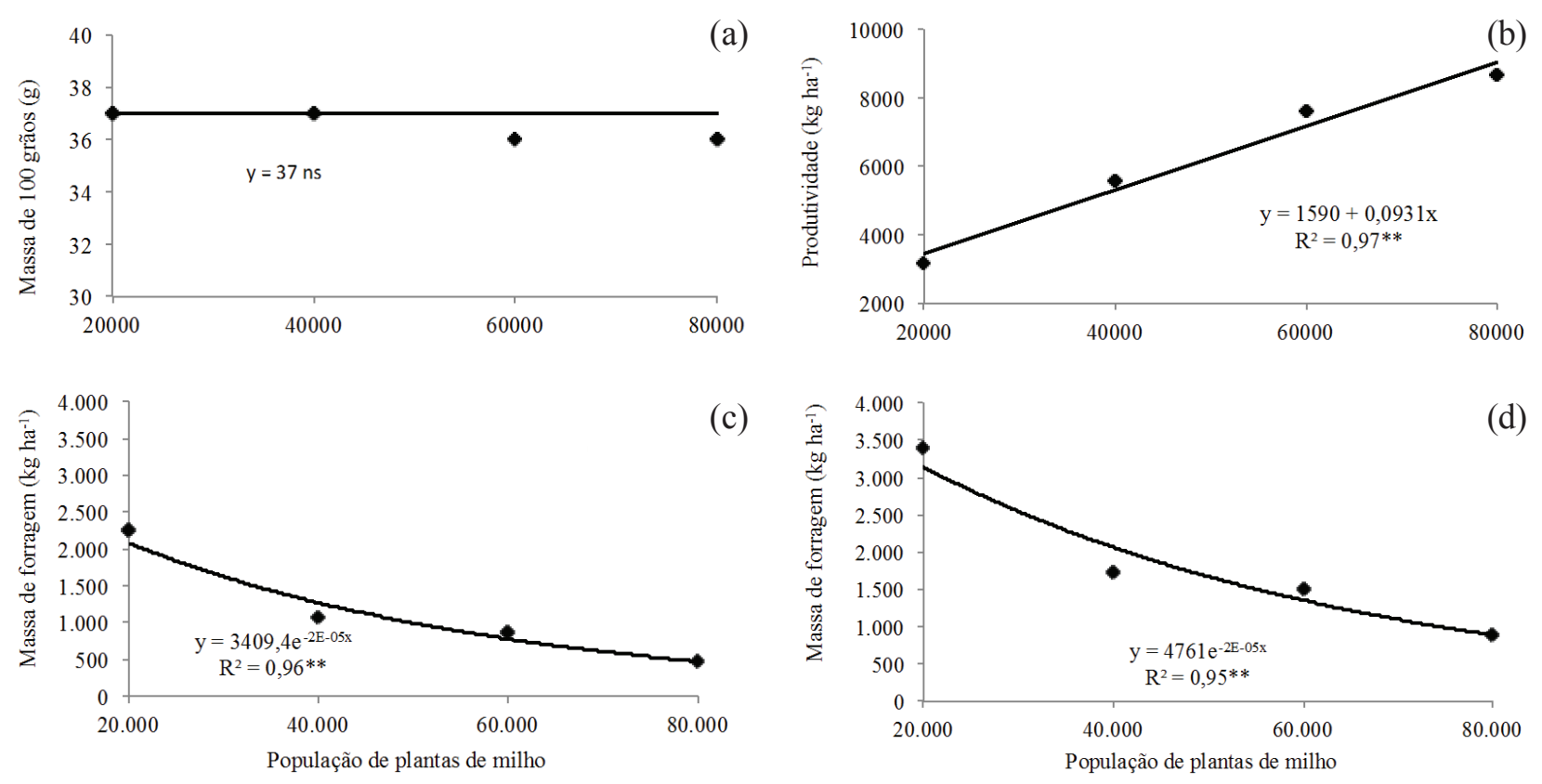

Figura 3. Massa de 100 grãos (a) e produtividade de grãos (b) de milho e massa de forragem de Brachiaria ruziziensis na colheita do milho (c) e 60 dias após a colheita do milho (d), em função da densidade populacional de plantas de milho (Ipameri, $\mathrm{GO}, 2012)$.

Sangoi (2001), Marchão et al. (2005), Cruz et al. (2007) e Calonego et al. (2011) também relataram redução no número de grãos fileira ${ }^{-1}$, com o aumento da densidade de plantas de milho, e justificaram que isto se deve ao incremento da competição intraespecífica por fotoassimilados, principalmente no estádio de florescimento da cultura, que proporciona o aumento da esterilidade feminina e, consequentemente, decréscimo no número de grãos espiga ${ }^{-1}$.

A produtividade de grãos de milho apresentou incremento linear, com o aumento da população de plantas (Figura 3b), sendo que, na maior densidade $\left(80.000\right.$ plantas $\left.\mathrm{a}^{-1}\right)$, a produtividade foi maior que $8.000 \mathrm{~kg} \mathrm{ha}^{-1}$, valor bem superior à média nacional da safrinha (4.577 $\mathrm{kg} \mathrm{ha}^{-1}$ ) (Conab 2012). Esta maior produtividade, em relação à média nacional, provavelmente ocorreu devido ao maior número de indivíduos por área, que compensou a maior produção por plantas, nas menores densidades de cultivo. Adicionalmente, as maiores precipitações pluviais (Tabela 2), que não causaram restrição hídrica ao desenvolvimento da cultura (Bergamaschi et al. 2004), proporcionaram o pleno desenvolvimento dos cultivos mais densos, pela diminuição na competição por água.

O aumento na produtividade de grãos da cultura, em função do aumento na densidade de plantas, pode ter ocorrido devido ao maior número de espigas $\mathrm{m}^{-2}$. Segundo Marchão et al. (2005), a produtividade do milho é significativamente influenciada pela densidade de plantas, sendo o número de espigas por área o principal fator deste aumento. Os autores verificaram, ainda, incremento na produtividade, com densidades superiores a 70.000 plantas ha ${ }^{-1}$, no espaçamento de $0,45 \mathrm{~m}$, na safra das águas.

Merotto Júnior et al. (1997) descreveram incrementos lineares na produtividade de grãos da cultura, com populações de 37.000-81.000 plantas ha ${ }^{-1}$, na safra das águas, nos espaçamentos de $0,75 \mathrm{~m} \mathrm{e} 1,0 \mathrm{~m}$, com produtividade variando de $7.500-10.000 \mathrm{~kg} \mathrm{ha}^{-1}$. Calonego et al. (2011) também obtiveram incrementos significativos na produtividade de grãos de milho, variando a população de 45.000 plantas ha $^{-1}$ para 75.000 plantas $\mathrm{ha}^{-1}$, na safra das águas, nos espaçamentos de $0,45 \mathrm{~m}$ e $0,90 \mathrm{~m}$. Pelos resultados obtidos, pode-se inferir que, caso haja adequado suprimento hídrico, pode-se aumentar a população de plantas de milho até 80.000 plantas ha-1, com incrementos significativos na produtividade de grãos. Como a densidade populacional de milho recomendada está entre 40.000 plantas ha $^{-1} \mathrm{e}$ 60.000 plantas ha $^{-1}$ (Embrapa 2006b), com base nos resultados, pode-se inferir que esta densidade pode estar sendo subdimensionada. 
Com relação ao consórcio, verificou-se que a planta forrageira não prejudicou o desenvolvimento do milho (Tabela 1), mesmo em densidades mais elevadas (80.000 plantas ha $\left.\mathrm{h}^{-1}\right)$. Resultados semelhantes foram descritos por outros autores, que trabalharam na época das águas e safrinha, com espaçamentos variando de $0,45 \mathrm{~m}$ a 1,0 $\mathrm{m}$ (Freitas et al. 2005 e 2008, Jakelaitis et al. 2004 e 2005, Ceccon 2008, Barducci et al. 2009, Pariz et al. 2009). Tais resultados advêm do fato de $U$. ruziziensis apresentar crescimento inicial lento (Freitas et al. 2008, Valle \& Pagliarini 2009) e, normalmente, não afetar o crescimento das plântulas de milho, que, contrariamente, possuem crescimento inicial rápido. $\mathrm{Na}$ maioria dos casos, o consórcio desta cultura com forrageiras perenes não acarreta em redução na produtividade de grãos (Cobucci 2001, Barducci et al. 2009), o que foi confirmado, na presente pesquisa.

A massa da forragem ajustou-se a uma equação polinomial de segundo grau (Figuras $3 \mathrm{c}$ e $3 \mathrm{~d}$ ), com menores valores nas maiores densidades de cultivo de milho. Desta forma, é provável que a maior população de plantas de milho possa ter reduzido a incidência de luz sobre o dossel das plantas de $U$. ruzizienis. Isto, possivelmente, limitou a fotossíntese e, consequentemente, a massa da forragem. Entretanto, mesmo que a maior densidade de cultivo de milho tenha afetado, significativamente, a massa da forragem, ainda assim foi vantajosa, pois não afetou a produtividade de grãos. Além disto, a colheita da forrageira aos 60 dias após a colheita do milho já proporcionou valores bem superiores da massa de forragem, variando de $3.378 \mathrm{~kg} \mathrm{ha}^{-1}$ de MS (densidade de 20.000 plantas ha $^{-1}$ ) a $872 \mathrm{~kg} \mathrm{ha}^{-1}$ de MS (densidade de 80.000 planta ha $^{-1}$ ) (Figura 3d).

Ceccon (2008) relatou acúmulo médio de $1.611 \mathrm{~kg} \mathrm{ha}^{-1}$ de $U$. ruziziensis, quando consorciada com milho, em população média de 46.298 plantas ha $^{-1}$, na época da safrinha. A massa de capim obtida na colheita do milho e aos 60 dias após o primeiro corte pode ser considerada baixa, principalmente nas maiores densidades de cultivo, uma vez que esta forrageira tem potencial para massa de forragem em torno de 20,0 $\mathrm{Mg} \mathrm{ha}^{-1}$ (Cobucci 2001, Kluthcouski et al. 2003).

Essa baixa produtividade pode ser explicada porque, após a colheita do milho, a colhedora ceifou parte da forrageira, reduzindo sua área foliar, em um período em que o dossel forrageiro ainda estava em formação e que a precipitação pluvial começava a diminuir significativamente, principalmente na região dos Cerrados, onde, em algumas localidades, também podem ocorrer temperaturas abaixo de $15^{\circ} \mathrm{C}$. De acordo com Costa et al. (2005), a faixa ideal de temperatura, para o desenvolvimento da brachiaria, é entre $30^{\circ} \mathrm{C}$ e $35^{\circ} \mathrm{C}$, enquanto, para temperaturas entre $10^{\circ} \mathrm{C}$ e $15^{\circ} \mathrm{C}$, seu crescimento é, praticamente, zero.

Entretanto, como a U. ruziziensis possui hábito perene e facilidade de rebrote, após as primeiras chuvas de setembro, é provável que, na época do semeio das culturas de verão (novembro), já existissem quantidades satisfatórias (mais de $10.000 \mathrm{~kg} \mathrm{ha}^{-1} \mathrm{de}$ MS), na superfície do solo, que pudessem ser utilizadas como palhada, no SPD (Kluthcouski et al. 2003, Pacheco et al. 2011, Nascente \& Crusciol 2012).

\section{CONCLUSÕES}

1. A produtividade de grãos de milho não foi alterada pelo consórcio com Brachiaria ruziziensis.

2. Maiores densidades de cultivo do milho (até 80.000 plantas $h^{-1}$ ) proporcionaram redução no número de espigas planta $^{-1}$ e de grãos fileira ${ }^{-1}$, na espiga, porém, possibilitaram maior produtividade de grãos, na área cultivada.

3. A massa da forragem de Brachiaria ruziziensis, em cultivo consorciado com o milho, em safrinha, reduziu-se à medida em que aumentou-se a densidade de cultivo do milho, até 80.000 plantas ha-1.

4. Na ausência de restrição hídrica, recomenda-se a densidade de 80.000 plantas de milho ha-1.

\section{REFERÊNCIAS}

ALVAREZ, C. G. D.; PINHO, R. G.; BORGES, I. D. Evaluation of agronomic characteristics and production of forage and grains of corn in different densities of sowing and row spacing. Ciência e Agrotecnologia, Lavras, v. 30, n. 3, p. 402-408, 2006.

BARDUCCI, R. S. et al. Produção de Brachiaria brizantha e Panicum maximum com milho e adubação nitrogenada. Archivos de Zootecnia, Córdoba, v. 58, n. 222, p. 211222, 2009.

BERGAMASCHI, H. et al. Distribuição hídrica no período crítico do milho e produção de grãos. Pesquisa Agropecuária Brasileira, Brasília, DF, v. 39, n. 9, p. 831839, 2004.

BORGHI, E.; CRUSCIOL, C. A. C. Produtividade de milho, espaçamento e modalidade de consorciação com 
Brachiaria brizantha no SPD. Pesquisa Agropecuária Brasileira, Brasília, DF, v. 42, n. 2, p. 163-171, 2007.

CALONEGO, J. C. et al. Produtividade e crescimento de milho em diferentes arranjos de plantas. Revista Agrarian, Dourados, v. 4, n. 12, p. 84-90, 2011.

CARVALHO, P. C. F. et al. Managing grazing animals to achieve nutrient cycling and soil improvement in no-till integrated systems. Nutrient Cycling in Agroecosystems, New York, v. 88, n. 2, p. 259-273, 2010.

CASTRO FILHO, C. et al. Tillage methods and soil and water conservation in Southern Brazil. Soil Tillage and Research, Amsterdan, v. 20, n. 2-4, p. 271-293, 1991.

CECCON, G. Milho safrinha com braquiária em consórcio. Dourados: Embrapa Agropecuária Oeste, 2008. (Comunicado técnico, 140).

COBUCCI, T. Manejo integrado de plantas daninhas em sistema plantio direto. In: ZAMBOLIM, L. (Ed.). Manejo integrado fitossanidade: cultivo protegido, pivô central e plantio direto. Viçosa: UFV, 2001. p. 583-624.

COMPANHIA NACIONAL DE ABASTECIMENTO (Conab). Levantamento da produção de grãos - safra 2011/12. 2012. Disponível em: <www.conab.gov.br>. Acesso em: 25 jun. 2012.

COSTA, K. A. de P.; ROSA, B.; OLIVEIRA, I. P. de et al. Efeito da estacionalidade na produção de matéria seca e composição bromatológica da Brachiaria brizantha $\mathrm{cv}$. Marandu. Ciência Animal Brasileira, Goiânia, v. 6, n. 3, p. 187-193, 2005.

CRUSCIOL, C. A. C. et al. An innovative crop-forage intercrop system: early cycle soybean cultivars and palisadegrass. Agronomy Journal, Madison, v. 104, n. 4, p. 1085-1095, 2012.

CRUSCIOL, C. A. C. et al. Benefits of integrating crops and tropical pastures as systems of production. Better Crops International, Atlanta, v. 94, n. 1, p. 14-16, 2010.

CRUZ, J. C. et al. Resposta de cultivares de milho à variação em espaçamento e densidade. Revista Brasileira de Milho e Sorgo, Sete Lagoas, v. 6, n. 1, p. 60-73, 2007.

DEMÉTRIO, C. S. et al. Performance of maize hybrids submitted to different row spacing and population densities. Pesquisa Agropecuária Brasileira, Brasília, DF, v. 43, n. 12, p. 1691-1697, 2008.

EMPRESA BRASILEIRA DE PESQUISA AGROPECUÁRIA (Embrapa). Centro Nacional de Pesquisa de Solos. Sistema brasileiro de classificação de solos. 2. ed. Rio de Janeiro: Embrapa Solos, 2006a.

EMPRESA BRASILEIRA DE PESQUISA AGROPECUÁRIA (Embrapa). Centro Nacional de Pesquisa de Milho e Sorgo. Cultivo do milho. 2. ed. Sete Lagoas: Embrapa Milho e Sorgo, 2006b.
FERREIRA, A. C. de B. et al. Produção de biomassa por cultivos de cobertura do solo e produtividade do algodoeiro em plantio direto. Pesquisa Agropecuária Brasileira, Brasília, DF, v. 45, n. 6, p. 546-553, 2010.

FREITAS, F. C. L. et al. Comportamento de cultivares de milho no consórcio com Brachiaria brizantha na presença e ausência de foramsulfuron + iodosulfuron-methyl para o manejo da forrageira. Planta Daninha, Viçosa, v. 26, n. 4, p. 215-221, 2008 .

FREITAS, F. C. L. et al. Formação de pastagem via consórcio de Brachiaria brizantha com o milho para silagem no sistema de plantio direto. Planta Daninha, Viçosa, v. 23, n. 1, p. 49-58, 2005.

GARCIA, R. A. et al. Potassium cycling in a cornbrachiaria cropping system. European Journal of Agronomy, Montpellier, v. 28, n. 4, p. 579-585, 2008.

INSTITUTO NACIONAL DE METEOROLOGIA (Inmet). Clima/ Faixa normal de precipitação. 2012. Disponível em: <http://www.inmet.gov.br/webcdp/ climatologia/faixa_normal/mostra_info.php $>$. Acesso em: 28 dez. 2012.

JAKELAITIS, A. et al. Influência de herbicidas e de sistemas de semeadura de Brachiaria brizantha consorciada com milho. Planta Daninha, Viçosa, v. 23, n. 1, p. 59-67, 2005.

JAKELAITIS, A. et al. Manejo de plantas daninhas no consórcio de milho com capim-braquiária (Brachiaria decumbens). Planta Daninha, Viçosa, v. 22, n. 4, p. 553560, 2004.

KLUTHCOUSKI, J. et al. Sistema Santa Fé - tecnologia Embrapa: integração lavoura-pecuária pelo consórcio de culturas anuais com forrageiras, em áreas de lavoura, nos sistemas direto e convencional. Santo Antônio de Goiás: Embrapa Arroz e Feijão, 2000. (Circular técnica, 38).

KLUTHCOUSKI, J. et al. (Ed). Integração lavourapecuária. Santo Antônio de Goiás: Embrapa Arroz e Feijão, 2003.

LARA-CABEZAS, W.A. R.; PÁDUA, R. V. de. Eficiência e distribuição de nitrogênio aplicado em cobertura na cultura de milho consorciada com Brachiaria ruziziensis, cultivada no sistema Santa Fé. Bragantia, Campinas, v. 66, n. 1, p. 131-140, 2007.

MARCHÃO, R. L. et al. Densidade de plantas e características agronômicas de híbridos de milho sob espaçamento reduzido entre linhas. Pesquisa Agropecuária Tropical, Goiânia, v. 35, n. 2, p. 93-101, 2005.

MEROTTO JÚNIOR, A.; ALMEIDA, M. L.; FUCHS, O. Aumento no rendimento de grãos de milho através do aumento da população de plantas. Ciência Rural, Santa Maria, v. 27, n. 4, p. 549-554, 1997. 
NASCENTE, A. S. et al. Desenvolvimento e produtividade de cultivares de arroz de terras altas em função do manejo do solo. Pesquisa Agropecuária Tropical, Goiânia, v. 41, n. 2, p. 186-192, 2011.

NASCENTE, A. S.; CRUSCIOL, C. A. C. Cover crops and herbicide timing management on soybean yield under notillage system. Pesquisa Agropecuária Brasileira, Brasília, DF, v. 47, n. 2, p. 187-192, 2012.

PACHECO, L. P. et al. Produção de fitomassa e acúmulo e liberação de nutrientes por plantas de cobertura na safrinha. Pesquisa Agropecuária Brasileira, Brasília, DF, v. 46, n. 1, p. 17-25, 2011.

PARIZ, C. M. et al. Desempenhos técnicos e econômicos da consorciação de milho com forrageiras dos gêneros Panicum e Brachiaria em sistema de integração lavourapecuária. Pesquisa Agropecuária Tropical, Goiânia, v. 39, n. 4, p. 360-370, 2009.

PENARIOL, F. G. et al. Performance of maize cultivars sown in different row widths and population densities in off-season cultivation. Revista Brasileira de Milho e Sorgo, Sete Lagoas, v. 2, n. 2, p. 52-60, 2003.

PEREIRA, R. G. et al. Influência dos sistemas de manejo do solo sobre componentes de produção do milho e Brachiaria decumbens. Caatinga, Mossoró, v. 22, n. 1, p. 64-71, 2009.
SANGOI, L. Understanding plant density effects on maize growth and development: an important issue to maximize grain yield. Ciência Rural, Santa Maria, v. 31, n. 1, p. 159168, 2001.

SANGOI, L. et al. Influence of row spacing reduction on maize grain yield in regions with a short summer. Pesquisa Agropecuária Brasileira, Brasília, DF, v. 36, n. 6, p. 861869, 2001.

SANTOS, R. S. M. et al. Componentes da parte aérea e raízes de pastagens de Brachiaria spp. em diferentes idades após a reforma, como indicadores de produtividade em ambiente de Cerrado. Pesquisa Agropecuária Tropical, Goiânia, v. 37, n. 2, p. 119-124, 2007.

SCALÉA, M. Plantio direto. Passo Fundo: Aldeia Norte, 2007.

VALLE, C. B.; PAGLIARINI, M. S. Biology, citogenetics, and breeding of Brachiaria. In: SINGH, R. J. (Ed.). Genetic resources, chromossome engineering, and crop managements. Boca Raton: CRC, 2009. p. 103-152.

VILELA, L. et al. Beneficios da integração entre lavoura e pecuária. Planaltina: Embrapa Cerrados, 2001. 